Supporting Information

\title{
Proton-Coupled Electron Transfer Kinetics for the Photoinduced Generation of a Cobalt(III)-Hydride Complex
}

\author{
Daniel A. Kurtz and Jillian L. Dempsey* \\ tDepartment of Chemistry, University of North Carolina at Chapel Hill, Chapel Hill, North \\ Carolina 27599-3290, United States
}




\section{Contents}

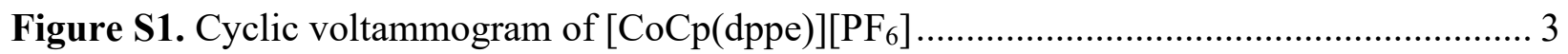

Figure S2. Plot of second-order decay of transient signal at $586 \mathrm{~nm}$ after excitation of $\operatorname{Ir}(\mathrm{ppy})_{3}$ at

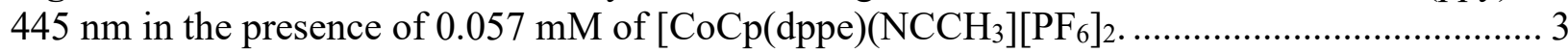

Figure S3. Plot of second-order decay of transient signal at $486 \mathrm{~nm}$ after excitation of $\operatorname{Ir}(\mathrm{ppy})_{3}$ at

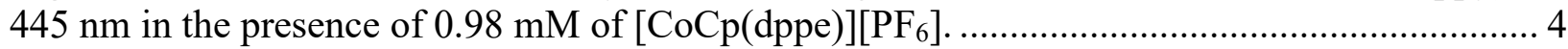

Figure S4. UV/vis absorbance titration of $\mathrm{Co}^{\mathrm{II}}$ with 4-methyl-anilinium tetrafluoroborate in

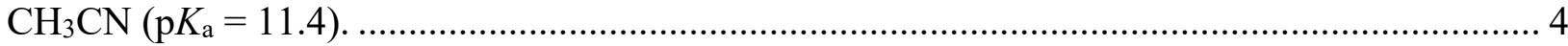

Figure S5. UV/vis absorbance titration of $\mathbf{C o}^{\mathrm{II}}$ with 4-methoxy-anilinium tetrafluoroborate in

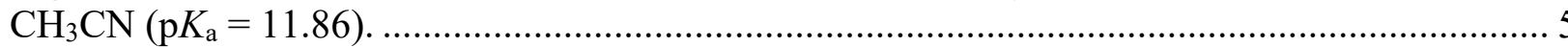

Figure S6. Cyclic voltammograms comparison between the orange product of the reaction

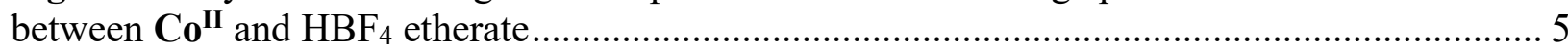

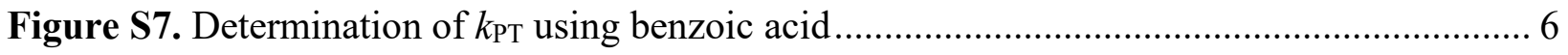

Figure S8. Determination of $k_{\mathrm{PT}}$ using 2,3,5,6-tetrafluorophenol.............................................. 7

Figure S9. Determination of $k_{\mathrm{PT}}$ using triethylammonium tetrafluoroborate. ……....................... 8

Figure S10. Determination of $k_{\mathrm{PT}}$ using 2,3,4,5,6-pentachlorophenol........................................ 9

Figure S11. Determination of $k_{\mathrm{PT}}$ using salicylic acid............................................................ 10

Figure S12. Determination of $k_{\text {РT }}$ using 2,3,5,6-tetrafluoro-4-trifluoromethylphenol.................. 11

Figure S 13. Comparison between proton transfer apparent rate constants determined from transient absorption measurements and those determined using peak shift analysis of cyclic

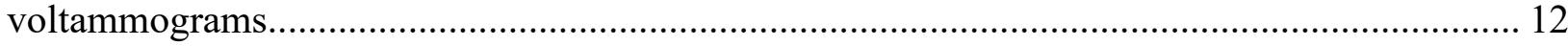

Scheme S1. Series of reactions that make up Equation 7 (main text)........................................ 13

Table S1 Results of ground state concentration calculations using above equations for 2,3,5,6-

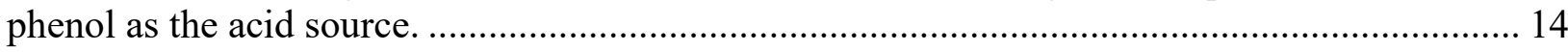

Figure S14. UV/vis absorbance titration of tetraethylammonium tetrafluorophenolate into an $\mathrm{CH}_{3} \mathrm{CN}$ solution of $\mathbf{C o}{ }^{\mathrm{II}}$

Figure S15. The transient signal at $855 \mathrm{~nm}$ after the excitation of IrIII in the presence of $1 \mathrm{mM}$ $\mathbf{C o}{ }^{\mathbf{I I}}$ indicates the short-lived formation of $\mathbf{I r}^{\mathbf{I V}}$ prior to its reduction by excess $\mathbf{C o} \mathbf{o}^{\mathbf{I I}}$ in solution.14

Differential equation function for MatLab kinetic simulations ........................................... 15

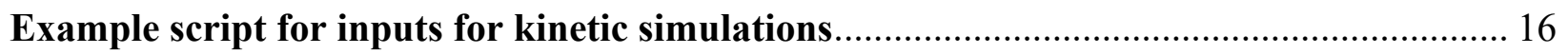




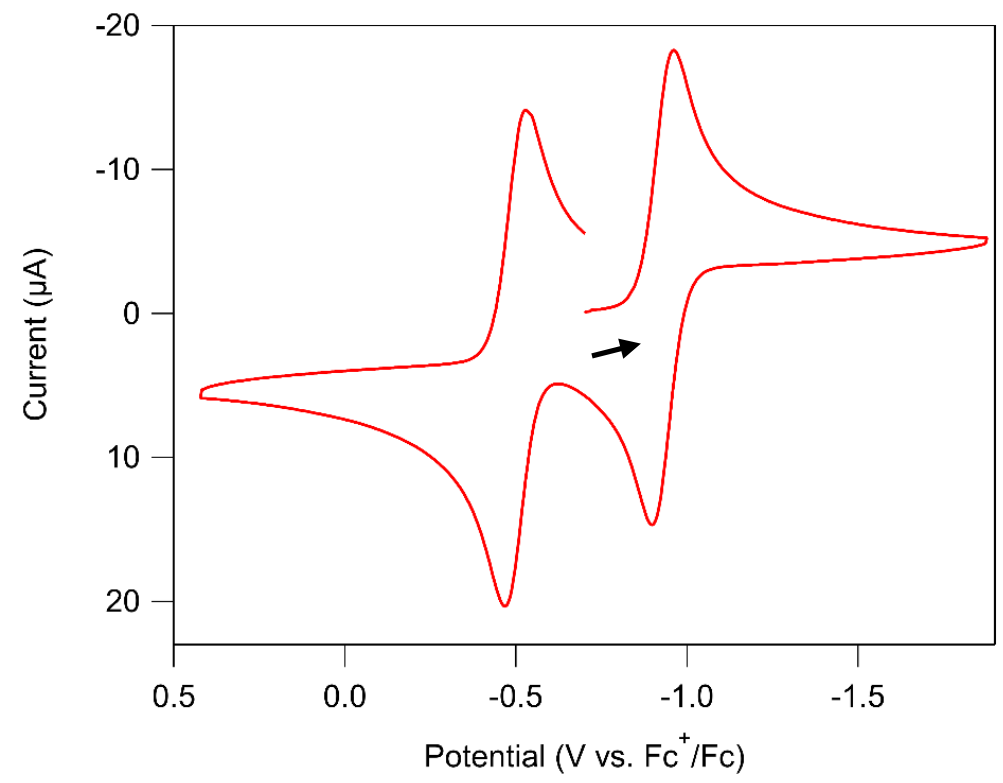

Figure S1. Cyclic voltammogram of $[\mathrm{CoCp}(\mathrm{dppe})]\left[\mathrm{PF}_{6}\right]$ recorded in $\mathrm{CH}_{3} \mathrm{CN}$ with $0.25 \mathrm{M}$ tetrabutylammonium hexafluorophosphate $\left[\mathrm{NBu}_{4}\right]\left[\mathrm{PF}_{6}\right]$. The open-circuit potential $(\mathrm{OCP})$ was determined prior to recording the cyclic voltammogram, and the scan was started at the OCP (arrow indication on the voltammogram).

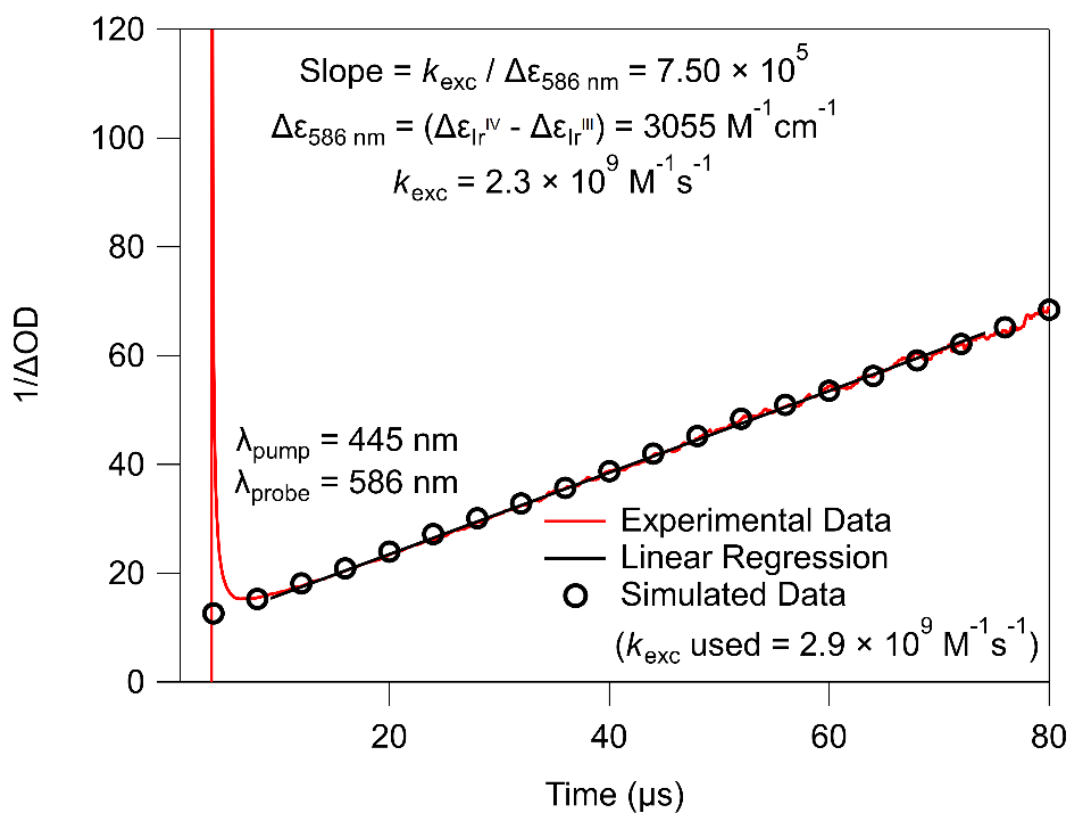

Figure S2. Plot of second-order decay of transient signal at $586 \mathrm{~nm}$ after excitation of $\operatorname{Ir}(\mathrm{ppy})_{3}$ at $445 \mathrm{~nm}$ in the presence of $0.057 \mathrm{mM}$ of $\left[\mathrm{CoCp}(\mathrm{dppe})\left(\mathrm{NCCH}_{3}\right]\left[\mathrm{PF}_{6}\right]_{2}\right.$. Using the slope of $1 / \Delta \mathrm{OD}$ vs time in the above region and the coefficients of the absorbing species, the $k_{\text {exc }}$ rate constant was determined to be $2.3 \times 10^{9} \mathrm{M}^{-1} \mathrm{~s}^{-1}$. The open circles are simulated data using MATLAB as described in the main text, but using a $k_{\mathrm{exc}}=2.9 \times 10^{9} \mathrm{M}^{-1} \mathrm{~s}^{-1}$. As discussed in the main text, the disparity may be due to interference from $\mathrm{CH}_{3} \mathrm{CN}$ ligand association/dissociation. 


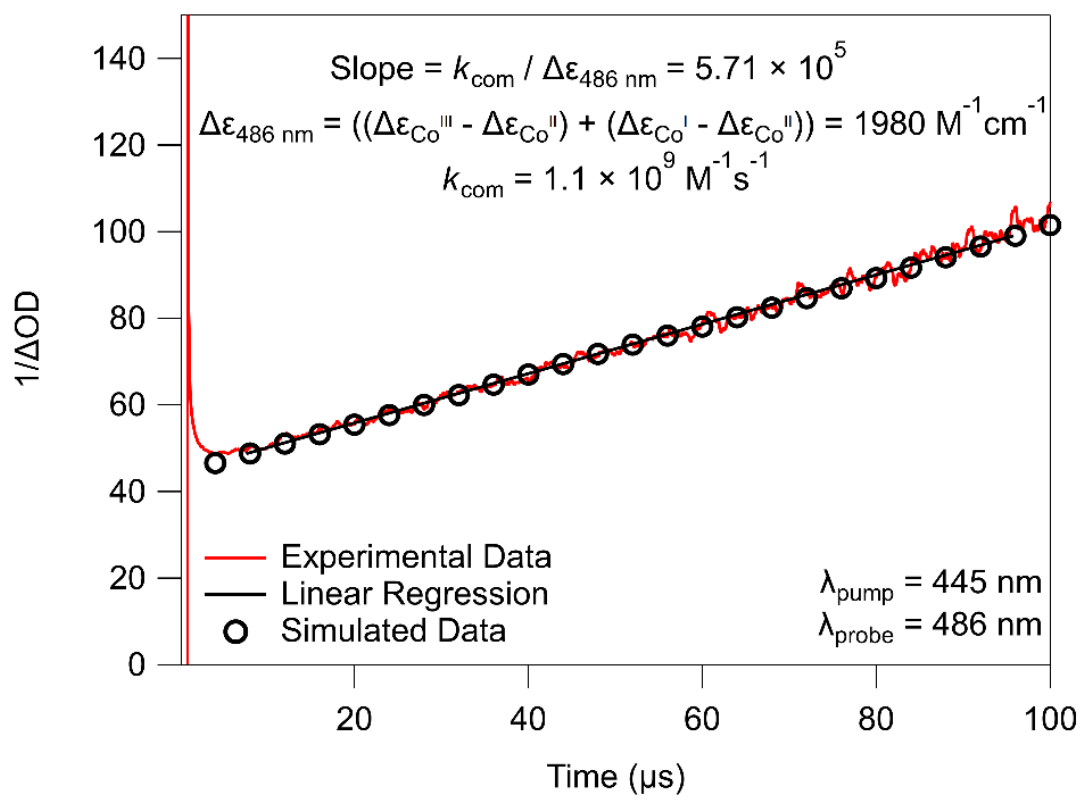

Figure S3. Plot of second-order decay of transient signal at $486 \mathrm{~nm}$ after excitation of $\operatorname{Ir}(\mathrm{ppy})_{3}$ at $445 \mathrm{~nm}$ in the presence of $0.98 \mathrm{mM}$ of $[\mathrm{CoCp}(\mathrm{dppe})]\left[\mathrm{PF}_{6}\right]$. Using the slope of $1 / \Delta \mathrm{OD}$ vs time in the above region and the coefficients of the absorbing species, the $k_{\mathrm{com}}$ rate constant was determined to be $1.1 \times 10^{9} \mathrm{M}^{-1} \mathrm{~s}^{-1}$. The open circles are simulated data using MATLAB as described in the main text, which show excellent agreement with the experimental data.

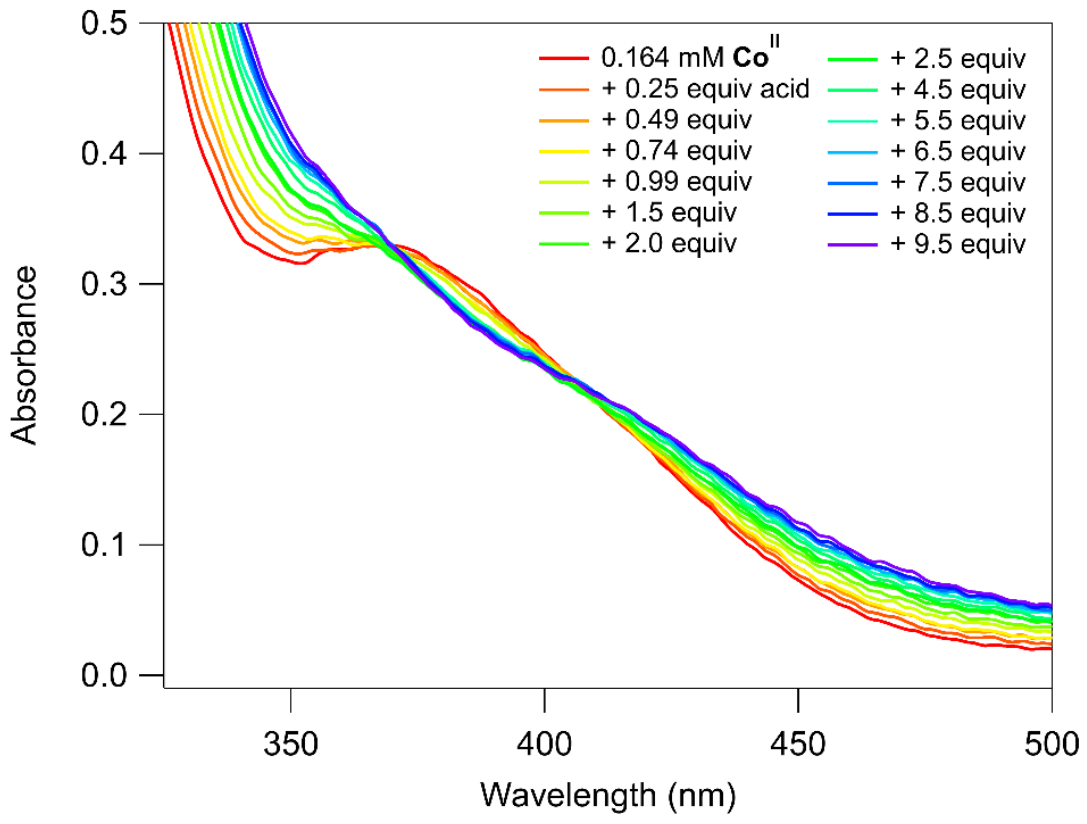

Figure S4. UV/vis absorbance titration of $\mathrm{Co}^{\mathrm{II}}$ with 4-methyl-anilinium tetrafluoroborate in $\mathrm{CH}_{3} \mathrm{CN}\left(\mathrm{p} K_{\mathrm{a}}=11.4\right)$. 


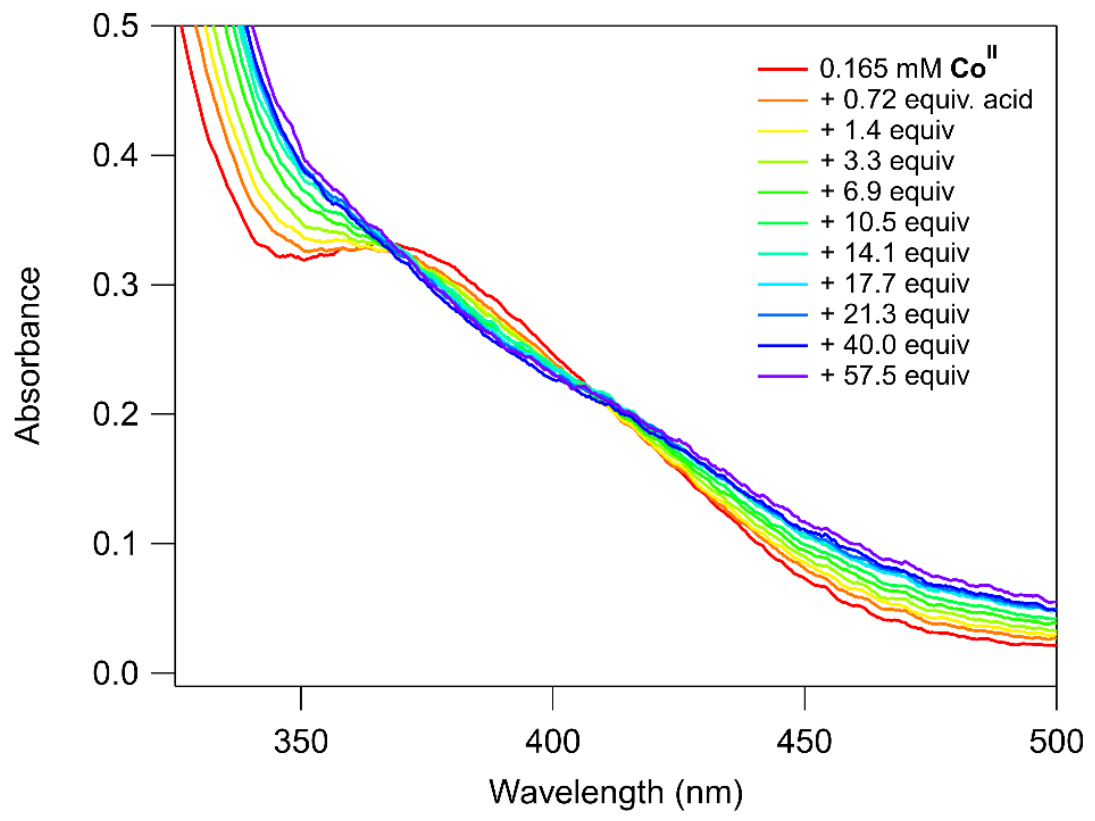

Figure S5. UV/vis absorbance titration of $\mathbf{C} \mathbf{0}^{\text {II }}$ with 4-methoxy-anilinium tetrafluoroborate in $\mathrm{CH}_{3} \mathrm{CN}\left(\mathrm{p} K_{\mathrm{a}}=11.86\right)$.

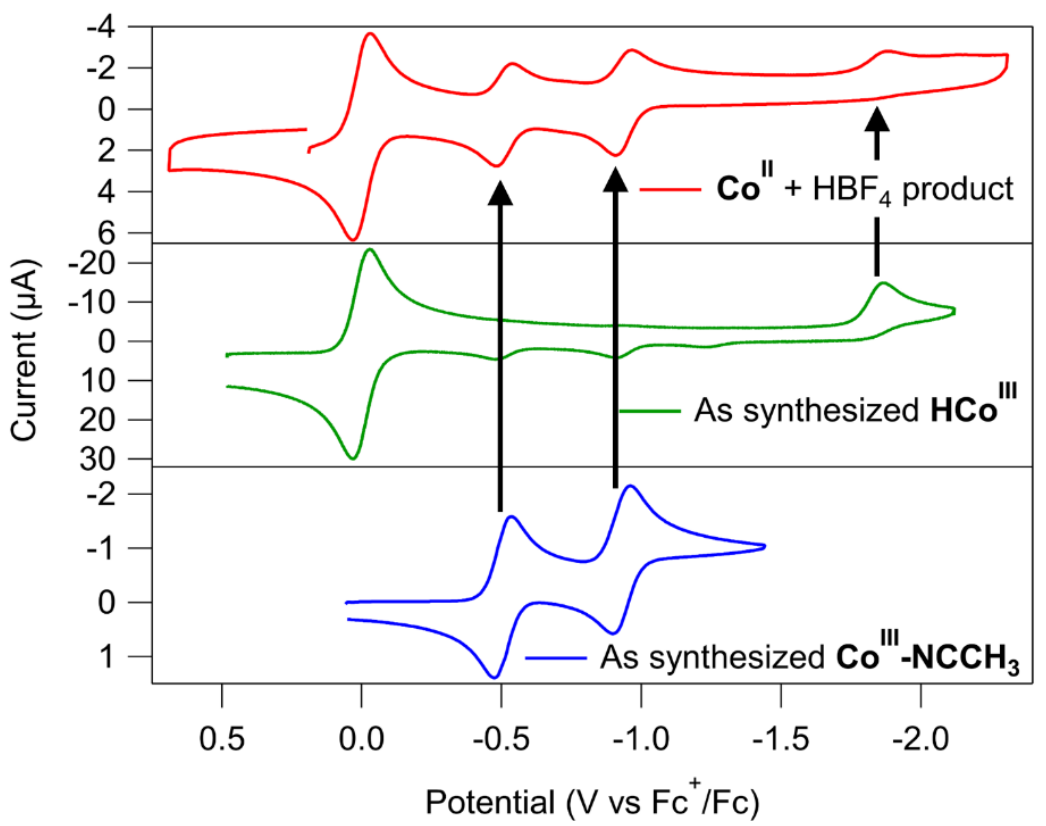

Figure S6. Cyclic voltammograms comparison between the orange product of the reaction between $\mathbf{C o}^{\mathrm{II}}$ and $\mathrm{HBF}_{4}$ etherate described in the main text (top), and authentic samples of $\mathbf{H C o}^{\mathrm{III}}$ (middle) and $\mathbf{C o}^{\mathrm{III}}-\mathbf{N C C H} 3$ (middle). Reversible waves at $\mathrm{E}_{1 / 2}=0 \mathrm{~V}$ are ferrocene added as an internal standard. 
Determination of $k_{\mathrm{PT}}$ using benzoic acid $\left(\mathrm{p} K_{\mathrm{a}}=21.51\right.$ in $\left.\mathrm{CH}_{3} \mathrm{CN}\right)$
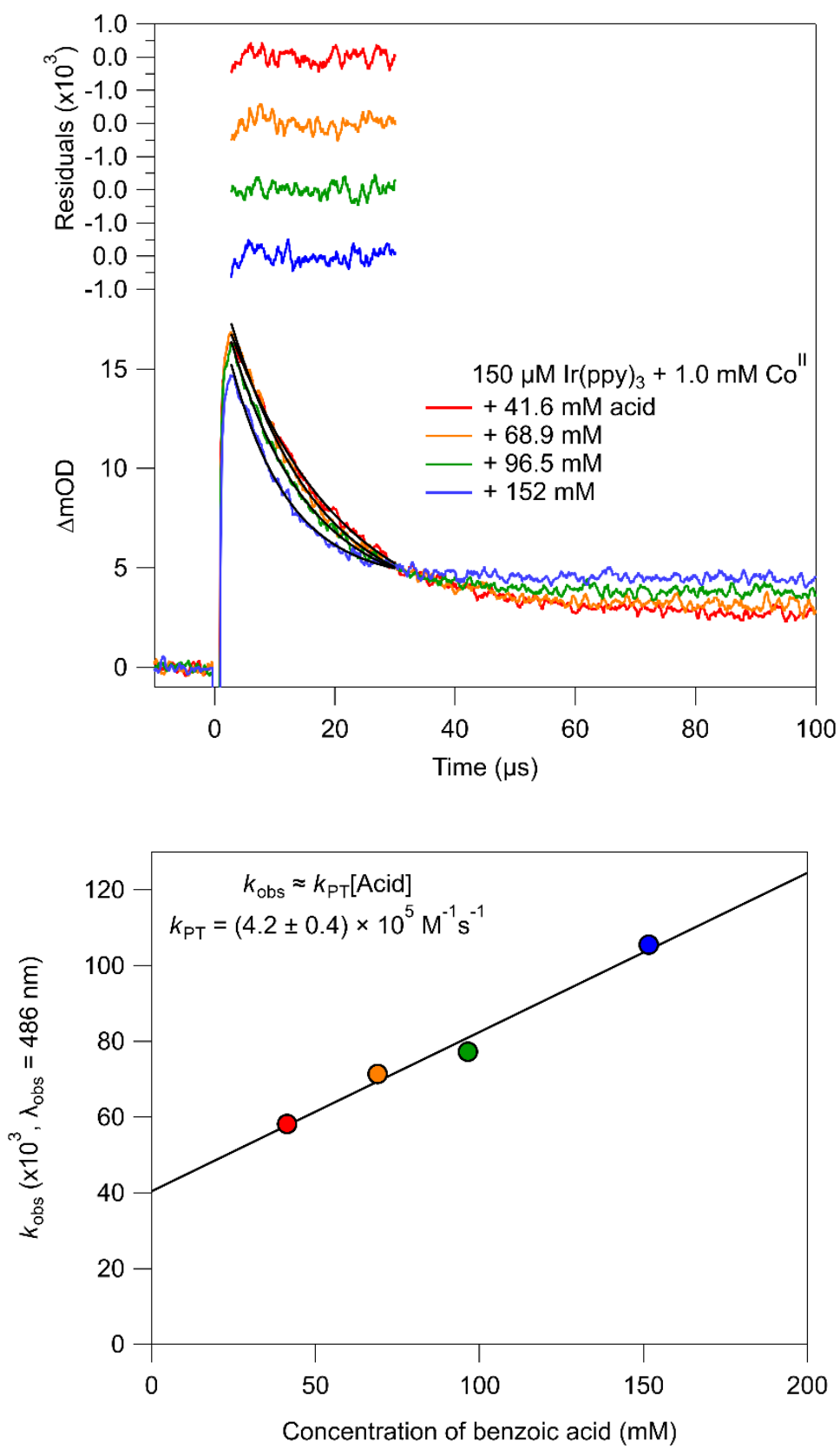

Figure S7. Determination of $k_{\mathrm{PT}}$ using benzoic acid. (Top) Transient absorption data for the transient signal at $486 \mathrm{~nm}$ with increasing concentrations of benzoic acid. The decay was first to a first order exponential decay in the range shown (residuals are shown). (Bottom) The observed rate constants from the exponential decays are displayed vs acid concentration, and the slope of the linear regression gives a second order protonation rate constant $\left(k_{\mathrm{PT}}\right)$ of $4.2 \times 10^{5} \mathrm{M}^{-1} \mathrm{~s}^{-1}$. 


\section{Determination of $k_{\mathrm{PT}}$ using 2,3,5,6-tetrafluorophenol $\left(\mathrm{p} K_{\mathrm{a}}=20.12\right.$ in $\left.\mathrm{CH}_{3} \mathrm{CN}\right)$}
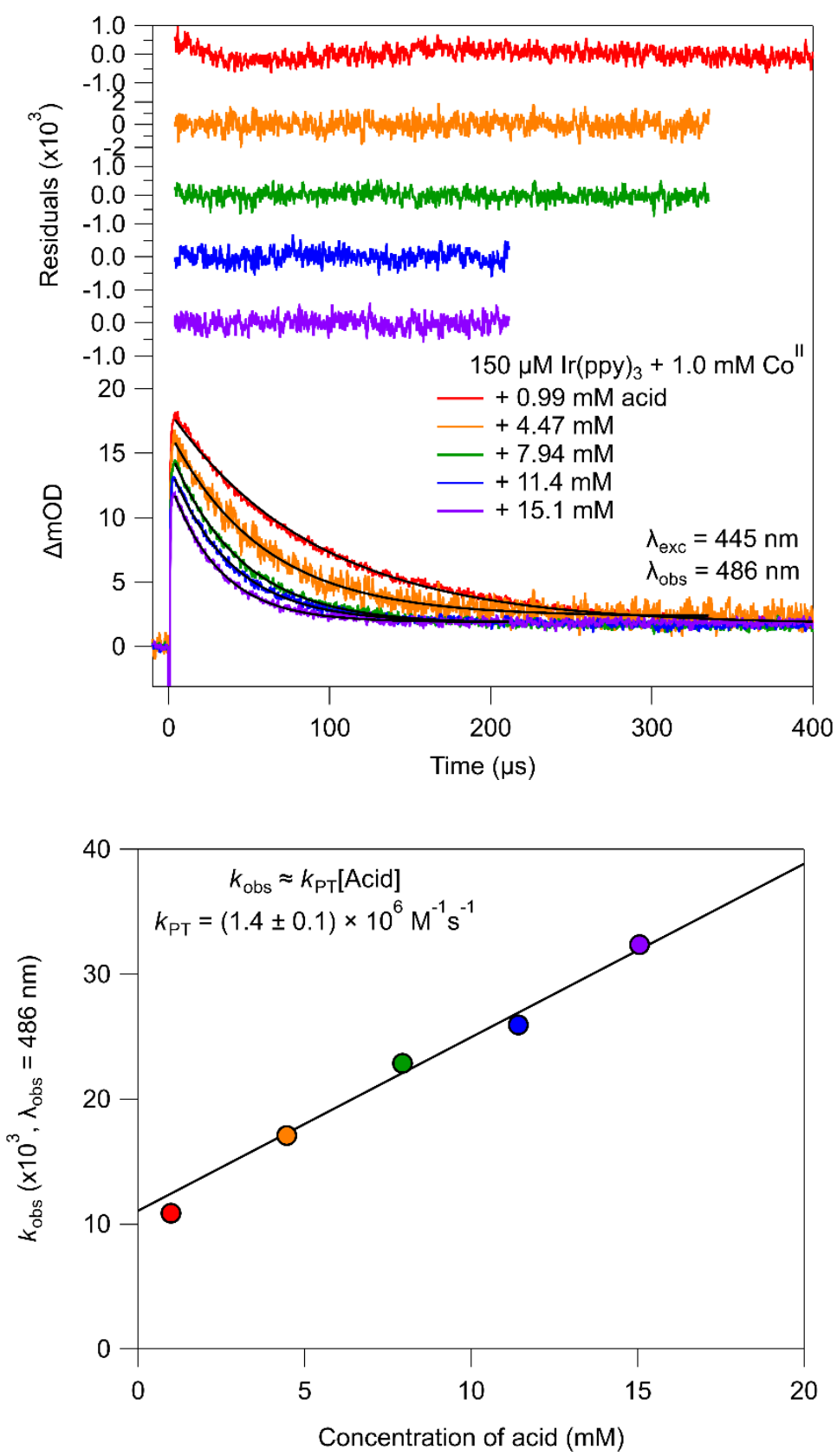

Figure S8. Determination of $k_{\mathrm{PT}}$ using 2,3,5,6-tetrafluorophenol. (Top) Transient absorption data for the transient signal at $486 \mathrm{~nm}$ with increasing concentrations of 2,3,5,6-tetrafluorophenol. The decay was first to a first order exponential decay in the range shown (residuals are shown). (Bottom) The observed rate constants from the exponential decays are displayed vs acid concentration, and the slope of the linear regression gives a second order protonation rate constant $\left(k_{\mathrm{PT}}\right)$ of $1.4 \times 10^{6} \mathrm{M}^{-1} \mathrm{~s}^{-1}$. 


\section{Determination of $k_{\mathrm{PT}}$ using triethylammonium tetrafluoroborate $\left(\mathrm{p} K_{\mathrm{a}}=18.82\right.$ in $\left.\mathrm{CH}_{3} \mathrm{CN}\right)$}
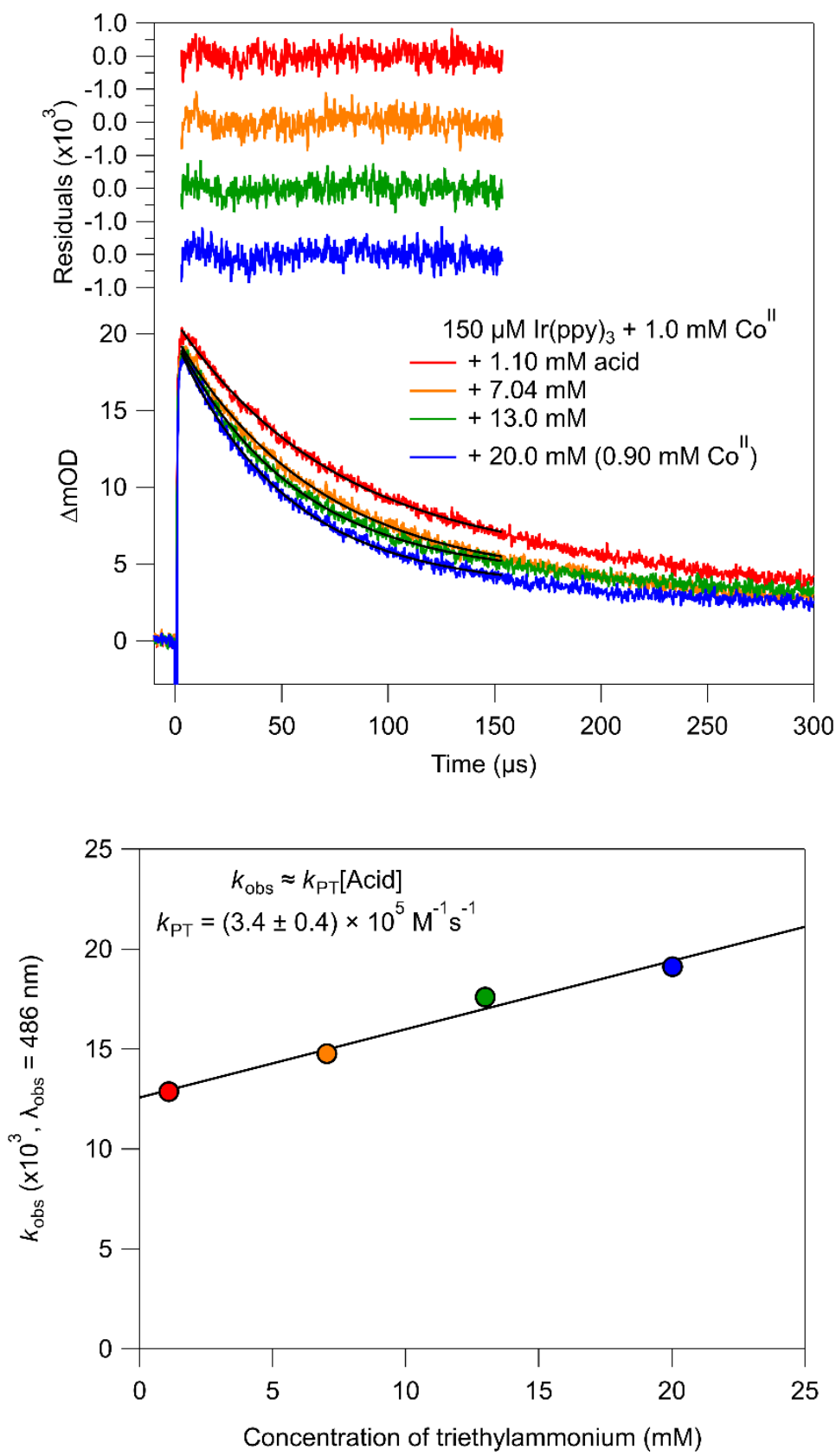

Figure S9. Determination of $k_{\mathrm{PT}}$ using triethylammonium tetrafluoroborate. (Top) Transient absorption data for the transient signal at $486 \mathrm{~nm}$ with increasing concentrations of triethylammonium tetrafluoroborate. The decay was first to a first order exponential decay in the range shown (residuals are shown). (Bottom) The observed rate constants from the exponential decays are displayed vs acid concentration, and the slope of the linear regression gives a second order protonation rate constant $\left(k_{\mathrm{PT}}\right)$ of $3.4 \times 10^{5} \mathrm{M}^{-1} \mathrm{~s}^{-1}$. 
Determination of $k_{\mathrm{PT}}$ using 2,3,4,5,6-pentachlorophenol $\left(\mathrm{p} K_{\mathrm{a}}=18.02\right.$ in $\left.\mathrm{CH}_{3} \mathrm{CN}\right)$
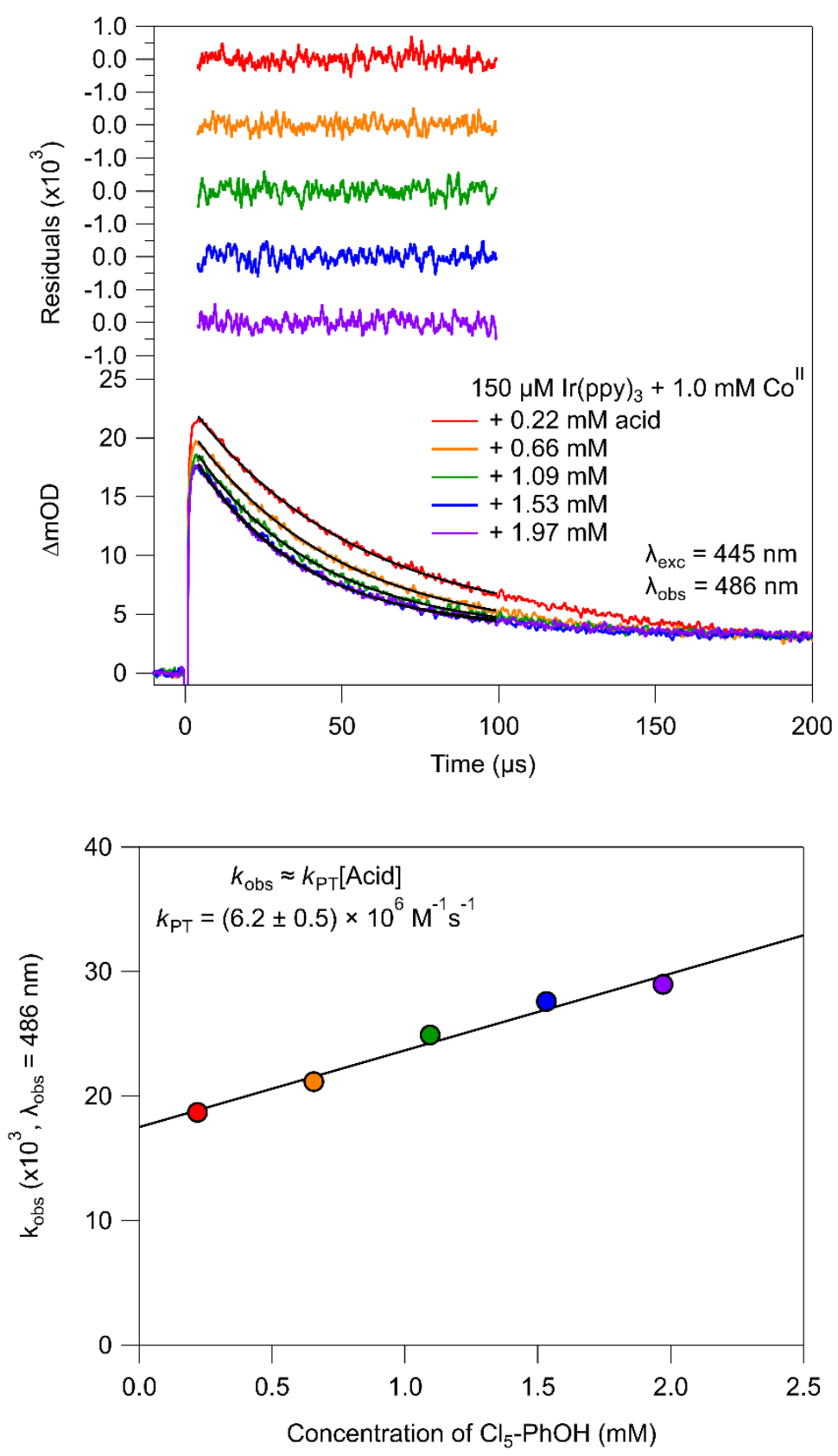

Figure S10. Determination of $k_{\text {PT }}$ using 2,3,4,5,6-pentachlorophenol. (Top) Transient absorption data for the transient signal at $486 \mathrm{~nm}$ with increasing concentrations of 2,3,4,5,6pentachlorophenol. The decay was first to a first order exponential decay in the range shown (residuals are shown). (Bottom) The observed rate constants from the exponential decays are displayed vs acid concentration, and the slope of the linear regression gives a second order protonation rate constant $\left(k_{\mathrm{PT}}\right)$ of $6.2 \times 10^{6} \mathrm{M}^{-1} \mathrm{~s}^{-1}$. 
Determination of $k_{\mathrm{PT}}$ using salicylic acid $\left(\mathrm{p} K_{\mathrm{a}}=16.7\right.$ in $\left.\mathrm{CH}_{3} \mathrm{CN}\right)$
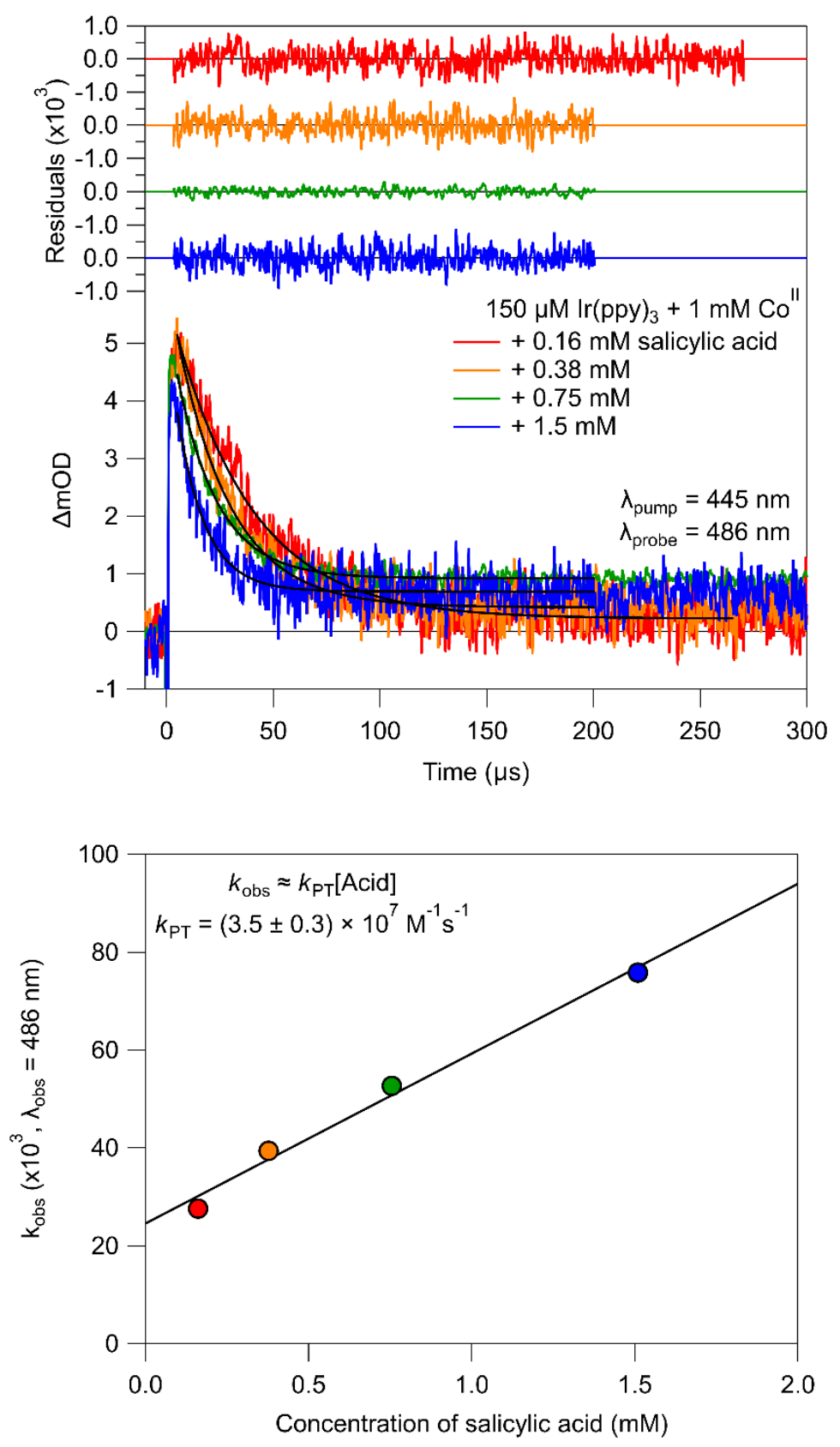

Figure S11. Determination of $k_{\mathrm{PT}}$ using salicylic acid. (Top) Transient absorption data for the transient signal at $486 \mathrm{~nm}$ with increasing concentrations of salicylic acid. The decay was first to a first order exponential decay in the range shown (residuals are shown). (Bottom) The observed rate constants from the exponential decays are displayed vs acid concentration, and the slope of the linear regression gives a second order protonation rate constant $\left(k_{\mathrm{PT}}\right)$ of $3.7 \times 10^{7} \mathrm{M}^{-1} \mathrm{~s}^{-1}$. 
Determination of $k_{\mathrm{PT}}$ using 2,3,5,6-tetrafluoro-4-trifluoromethylphenol $\left(\mathrm{p} K_{\mathrm{a}}=16.62\right.$ in $\mathrm{CH}_{3} \mathrm{CN}$ )
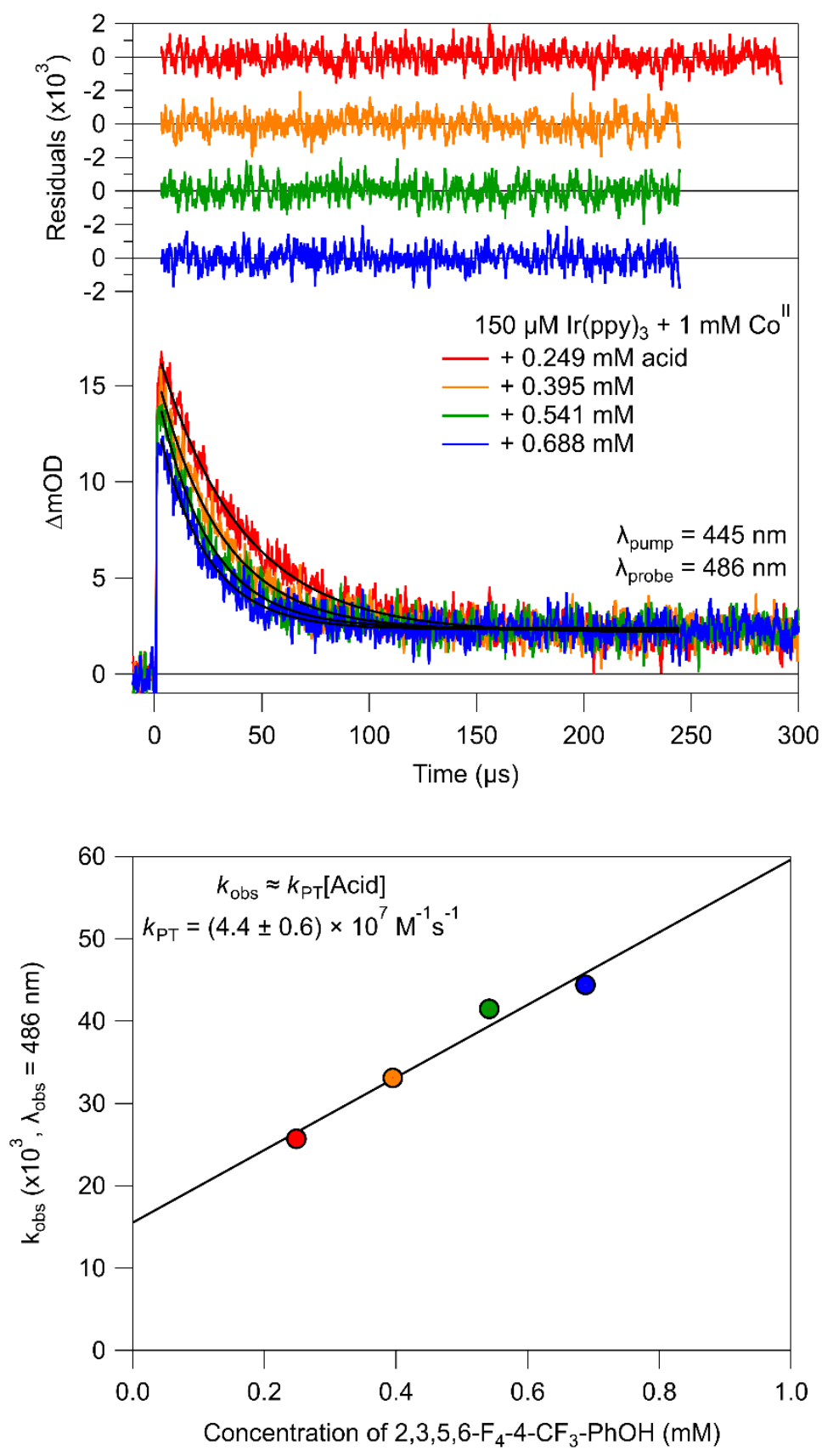

Figure S12. Determination of $k_{\mathrm{PT}}$ using 2,3,5,6-tetrafluoro-4-trifluoromethylphenol. (Top) Transient absorption data for the transient signal at $486 \mathrm{~nm}$ with increasing concentrations of 2,3,5,6-tetrafluoro-4-trifluoromethylphenol. The decay was first to a first order exponential decay in the range shown (residuals are shown). (Bottom) The observed rate constants from the exponential decays are displayed vs acid concentration, and the slope of the linear regression gives a second order protonation rate constant $\left(k_{\mathrm{PT}}\right)$ of $4.4 \times 10^{7} \mathrm{M}^{-1} \mathrm{~s}^{-1}$. 


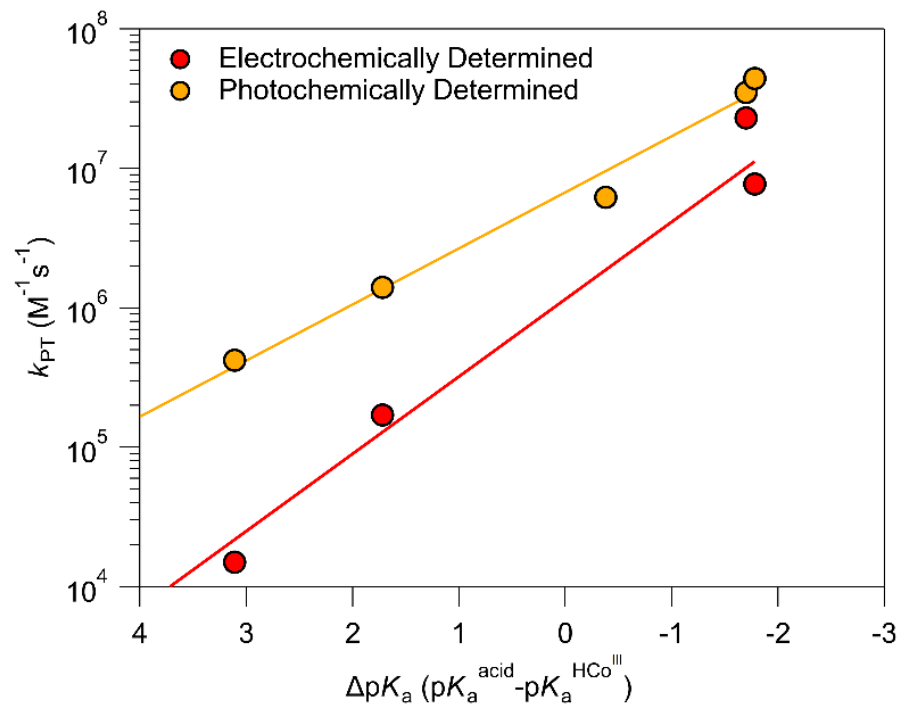

Figure S 13. Comparison between proton transfer apparent rate constants determined from transient absorption measurements and those determined using peak shift analysis of cyclic voltammograms. 
Scheme S1. Series of reactions that make up Equation 7 (main text).

The full reaction with equilibrium constant $K_{\mathrm{GS}}$ can be split up into the one electron reduction of $\mathbf{C o}^{\text {II }}$ to form $\mathbf{C o}^{\mathrm{I}}$, the one electron oxidation of $\mathbf{C o}^{\mathrm{II}}$ to form $\mathbf{C o}^{\mathrm{III}}$, the protonation of $\mathbf{C o}^{\mathrm{I}}$ to form $\mathrm{HCo}^{\text {III }}$, and the homoconjugation of the generated conjugate base with excess acid as shown below

$$
\begin{aligned}
& 2\left[\mathrm{Co}{ }^{\prime \prime} \mathrm{Cp}(\mathrm{dppe})\right]^{+}+2 \mathrm{HA} \stackrel{K_{\mathrm{GS}}}{\rightleftharpoons}\left[\mathrm{Co}_{\mathrm{III}} \mathrm{Cp}(\mathrm{dppe})\right]^{2+}+\left[\mathrm{HCo}_{\mid \mathrm{III}} \mathrm{Cp}(\mathrm{dppe})\right]^{+}+\mathrm{AHA}_{-} \\
& {\left[\mathrm{Co}^{\prime \prime} \mathrm{Cp}(\mathrm{dppe})\right]^{+\mathrm{e}^{-}} \rightleftharpoons{ }^{\mathrm{Co}_{\mathrm{I}}} \mathrm{Cp}(\mathrm{dppe}) \quad \Delta \mathrm{G}=-23.06^{*}\left(E^{0}\left(\mathrm{Co}^{\mathrm{I}}{ }^{1 / 1}\right)\right)}
\end{aligned}
$$

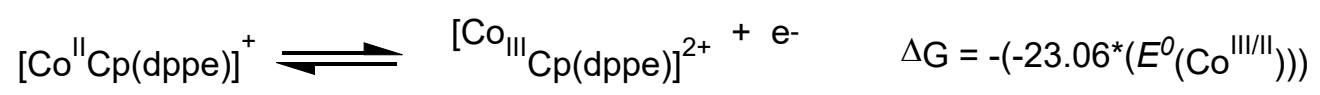

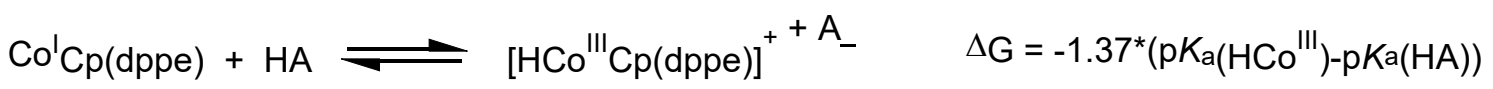

$$
\begin{aligned}
& \mathrm{A}^{-}+\mathrm{HA} \rightleftharpoons \mathrm{AHA}^{-} \quad \Delta \mathrm{G}=-\mathrm{RT}^{*} \ln \left(K_{\mathrm{a}}\right)
\end{aligned}
$$

Ground state concentration calculations for 2,3,5,6-tetrafluorophenol and $\mathbf{C o}$ II

$$
\begin{gathered}
E^{0}\left(\mathrm{Co}^{I I / I}\right)=-0.93 \mathrm{~V} \\
E^{0}\left(\mathrm{Co}^{I I I / I}\right)=-0.51 \mathrm{~V} \\
p K_{a}\left(H C \mathrm{Co}^{I I I}\right)=18.4 \\
p K_{a}(H A)=20.12 \\
K_{a}=10^{4.2}(\text { from ref } 1) \\
\Delta G_{G S}=(-23.06 \times-0.93)+(-(-23.06 \times-0.51))+(-1.37 \times(18.4-20.12))
\end{gathered}
$$$$
+\left(-\left(1.987 \times 10^{3}\right) \times 298 \times 10^{4.2}\right)=6.32 \mathrm{kcal} / \mathrm{mol}
$$$$
K_{G S}=e^{-\Delta G / R T}=2.35 \times 10^{-5} M^{-1}
$$

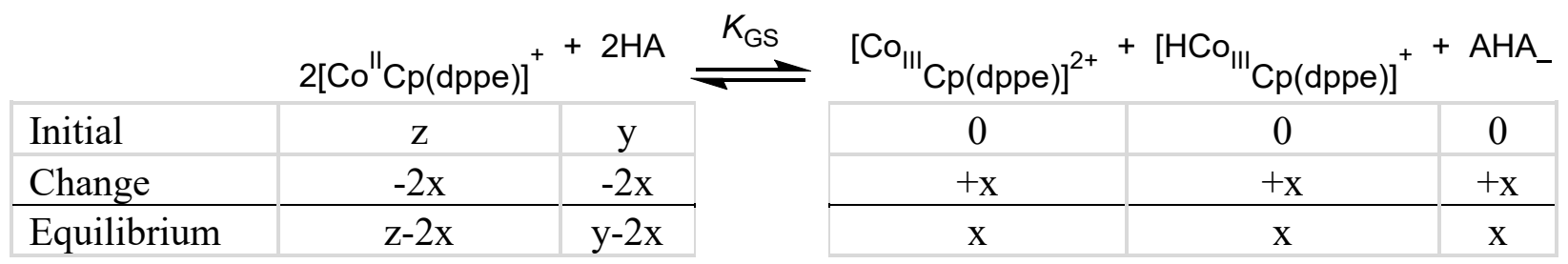

$$
\begin{gathered}
K_{G S}=\frac{x^{3}}{(z-2 x)^{2}(y-2 x)^{2}} \approx \frac{x^{3}}{z^{2} \times y^{2}} \\
x=\sqrt[3]{K_{G S} \times\left[C o^{I I}\right]^{2} \times[H A]^{2}}
\end{gathered}
$$

where $\mathrm{z}=\left[\mathbf{C o}^{\mathrm{II}}\right], \mathrm{y}=[\mathrm{HA}]$, and $\mathrm{x}=\left[\mathbf{C o}^{\mathrm{III}}\right]=\left[\mathbf{H C o}^{\mathrm{III}}\right]=\left[\mathrm{AHA}^{-}\right]$ 
Table S1 Results of ground state concentration calculations using above equations for 2,3,5,6phenol as the acid source.

\begin{tabular}{|c|c|c|c|}
\hline$\left[\mathbf{C o} \mathbf{o}^{\mathrm{II}}\right]$ added & {$[\mathrm{HA}]$ added } & Calculated value of $\mathrm{x}$ & $\begin{array}{c}\text { Value of } \mathrm{x} \text { used } \\
\text { in kinetic simulations }\end{array}$ \\
\hline $1.0 \mathrm{mM}$ & $0.99 \mathrm{mM}$ & $2.8 \mu \mathrm{M}$ & $2.2 \mu \mathrm{M}$ \\
\hline $1.0 \mathrm{mM}$ & $4.47 \mathrm{mM}$ & $7.7 \mu \mathrm{M}$ & $6.0 \mu \mathrm{M}$ \\
\hline $1.0 \mathrm{mM}$ & $7.94 \mathrm{mM}$ & $11.4 \mu \mathrm{M}$ & $10.0 \mu \mathrm{M}$ \\
\hline $1.0 \mathrm{mM}$ & $11.4 \mathrm{mM}$ & $14.5 \mu \mathrm{M}$ & $12.5 \mu \mathrm{M}$ \\
\hline $1.0 \mathrm{mM}$ & $15.1 \mathrm{mM}$ & $17.5 \mu \mathrm{M}$ & $16.0 \mu \mathrm{M}$ \\
\hline
\end{tabular}

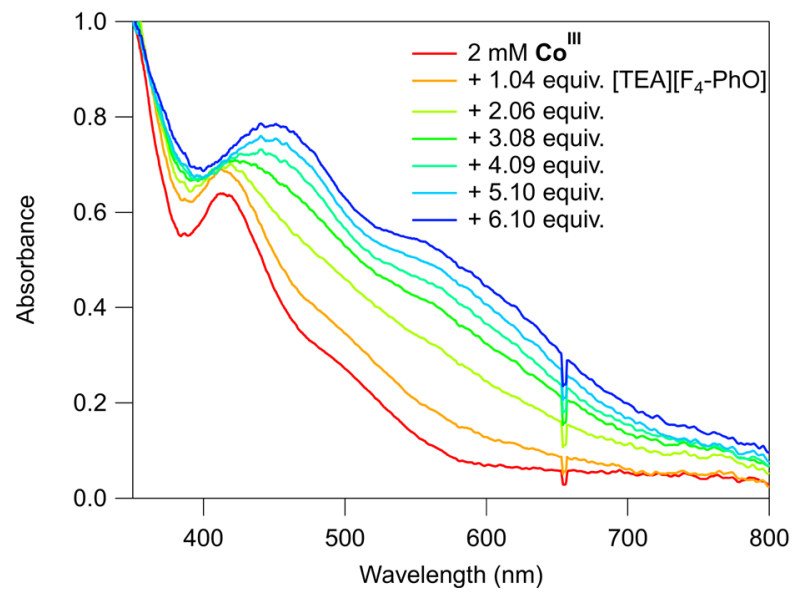

Figure S14. UV/vis absorbance titration of tetraethylammonium tetrafluorophenolate into an $\mathrm{CH}_{3} \mathrm{CN}$ solution of $\mathbf{C o}^{\text {II }}$. The equilibrium constant for ligand binding was determined at low equivalents of tetrafluorophenolate additions due to relevance to transient absorption experiments. At low ligand additions, $K_{\mathrm{L}}$ was determined to be $\sim 515 \mathrm{M}^{-1}$, and $\varepsilon_{486 \mathrm{~nm}}=1,975 \mathrm{M}^{-1}$ $\mathrm{cm}^{-1}$ for $\mathrm{Co}^{\mathrm{III}}$-A where $\mathrm{A}=2,3,5,6$-tetrafluorophenolate.

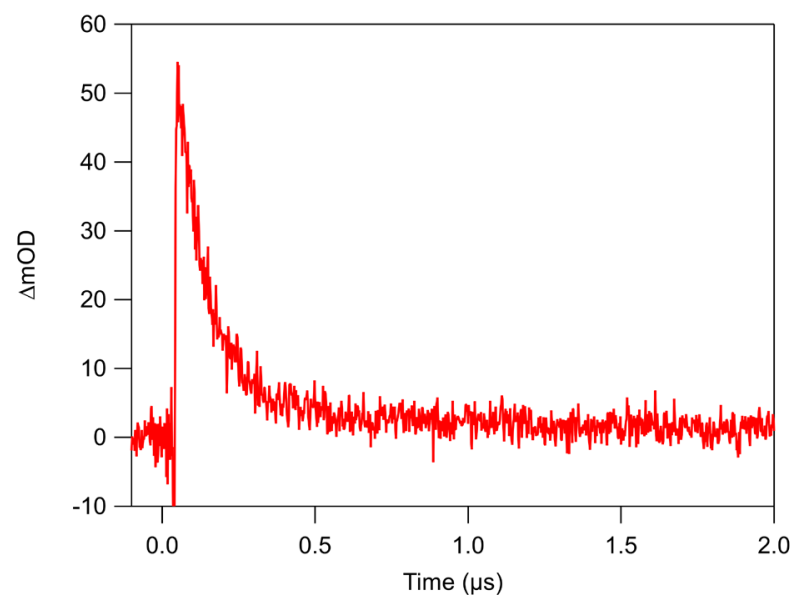

Figure S15. The transient signal at $855 \mathrm{~nm}$ after the excitation of Ir III in the presence of $1 \mathrm{mM}$ $\mathbf{C o}^{\mathbf{I I}}$ indicates the short-lived formation of $\mathbf{I r}^{\mathbf{I V}}$ prior to its reduction by excess $\mathbf{C} \mathbf{0}^{\mathrm{II}}$ in solution. 


\section{Differential equation function for MatLab kinetic simulations}

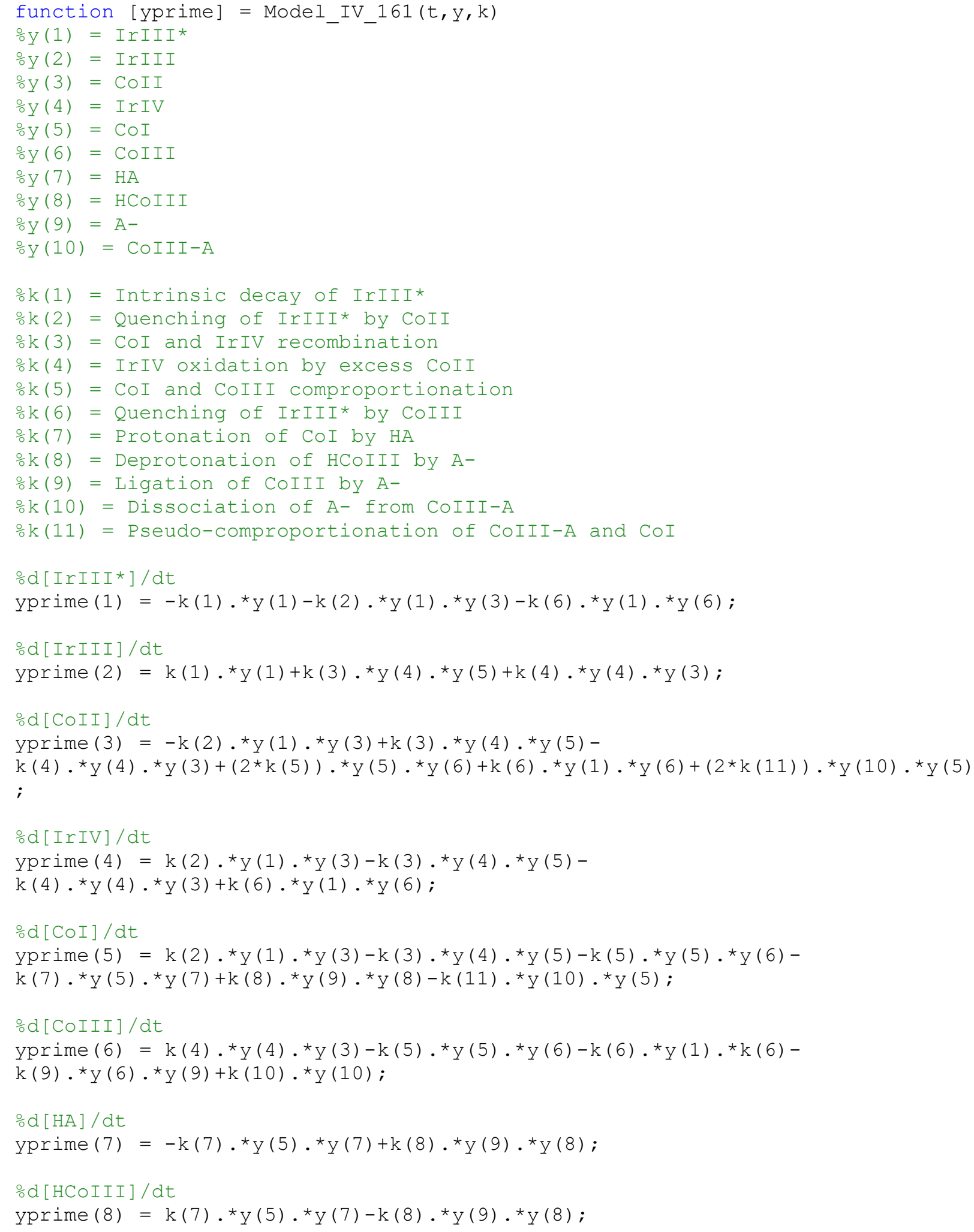




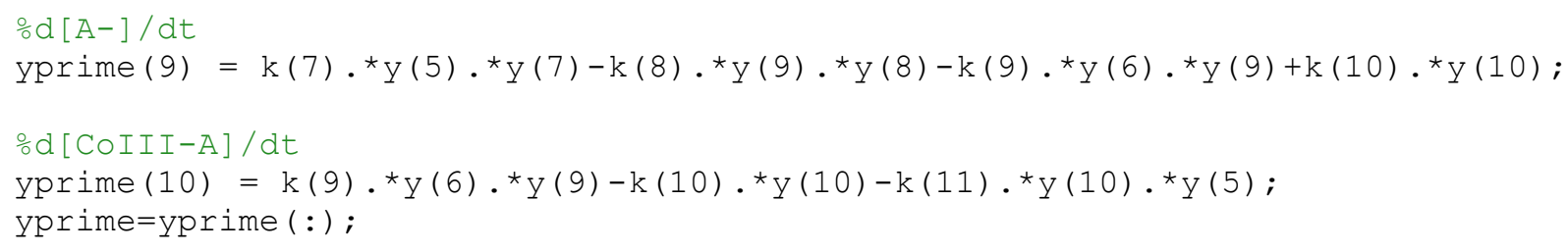

\section{Example script for inputs for kinetic simulations}

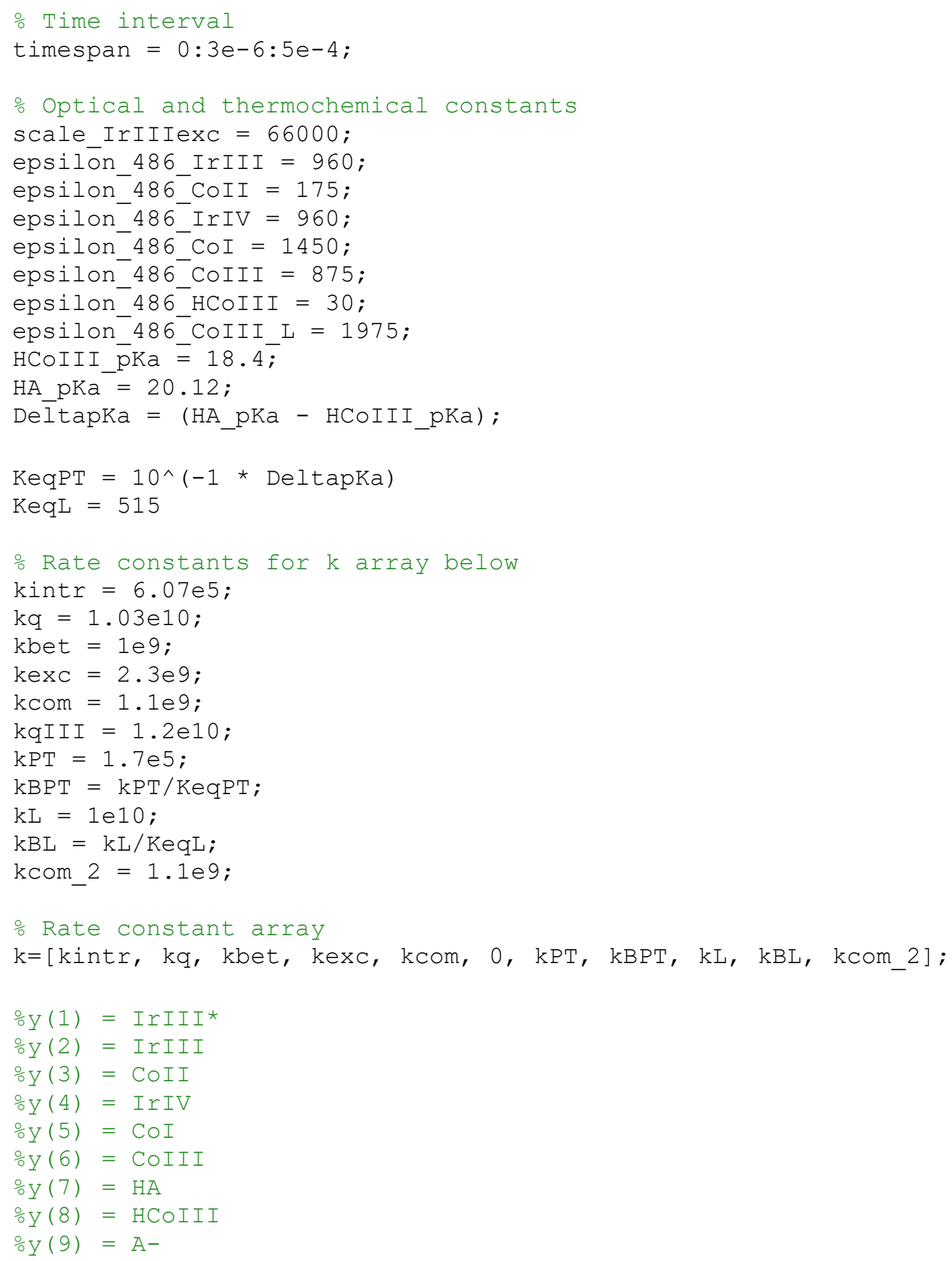




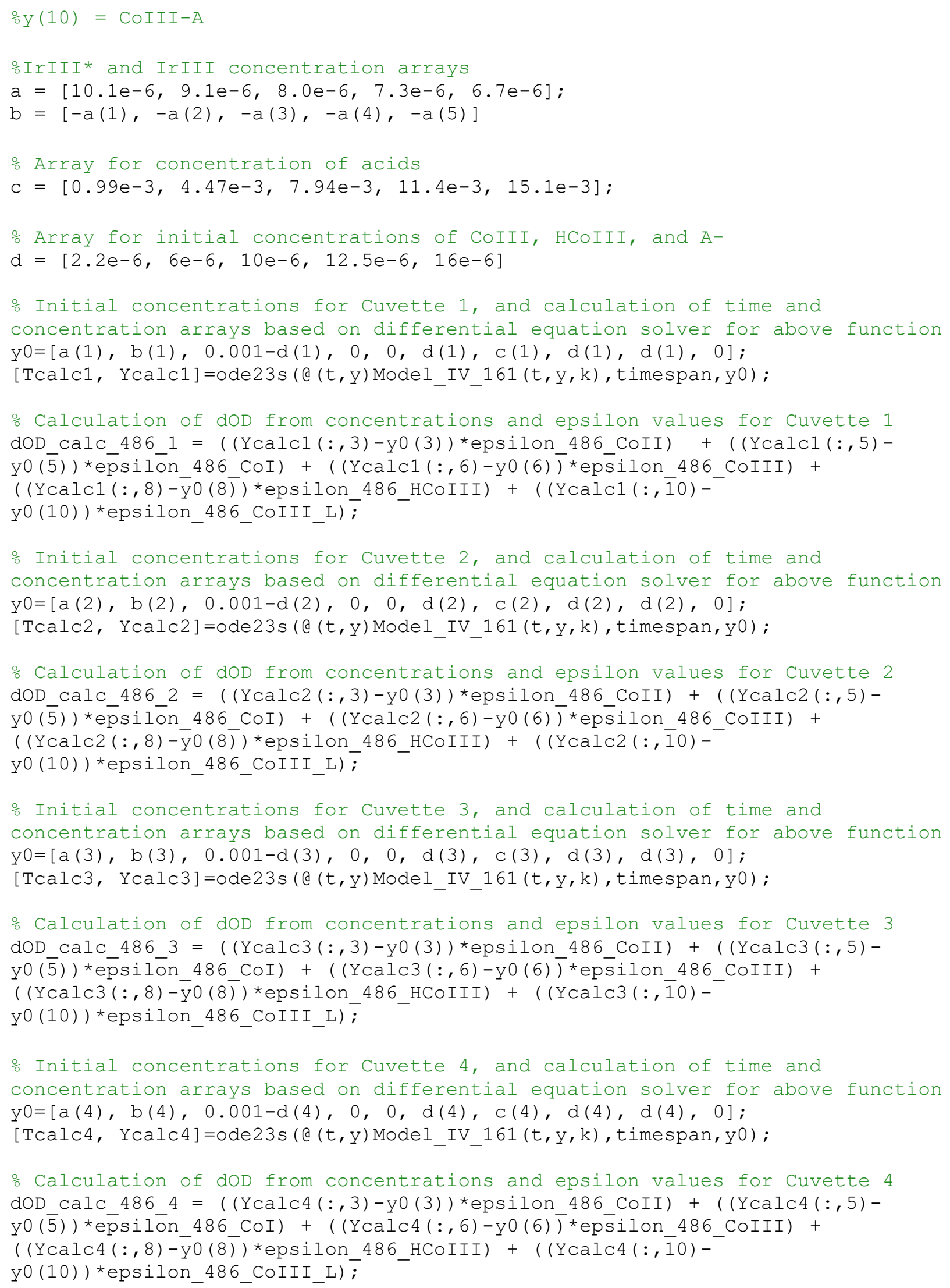




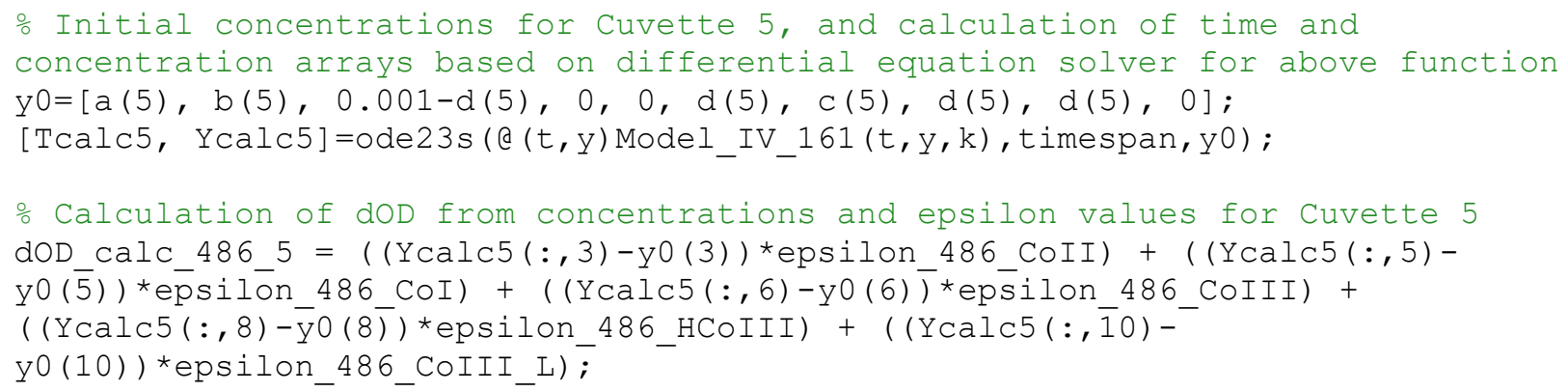

\section{Reference}

(1) Kütt, A.; Leito, I.; Kaljurand, I.; Sooväli, L.; Vlasov, V. M.; Yagupolskii, L. M.; Koppel, I. A. A Comprehensive Self-Consistent Spectrophotometric Acidity Scale of Neutral Brønsted Acids in Acetonitrile. J. Org. Chem. 2006, 71 (7), 2829-2838. 